\title{
CICLO REAL DE UM MOTOR DE IGNIÇÃO POR COMPRESSÃO QUE TRABALHA EM REGIME BICOMBUSTIIVEL: DIESEL E GÁS NATURAL
}

\author{
REAL CYCLE OF A COMPRESSION IGNITION ENGINE RUNNING IN DUAL-FUEL REGIME: DIESEL \\ AND NATURAL GAS
}

\author{
Miguel Neves Camargo ${ }^{1}$, José Fernando Schlosser ${ }^{2}$, Leoni Pentiado Godoy ${ }^{3}$, Nara Medianeira Stefano ${ }^{4}$ \\ ${ }^{1}$ Doutor, Professor de graduação do curso de Engenharia de Produção da Universidade Federal de Santa Maria, \\ RS. E-mail: mnevesc@brturbo.com.br \\ ${ }^{2}$ Doutor, Professor Titular do Departamento de Engenharia Rural e Diretor do Núcleo de Ensaios de Máquinas \\ Agrícolas da Universidade Federal de Santa Maria, RS. E-mail: josefernandoschlosser@ gmail.com \\ ${ }^{3}$ Doutora, Professora do Programa de Pós-Graduação em Engenharia de Produção da Universidade Federal de \\ Santa Maria, RS.E-mail: leoni@ smail.ufsm.br \\ ${ }^{4}$ Economista, Doutora em Engenharia de Produção, Pós-Doutoranda na UFPR. E-mail: \\ stefano.nara@gmail.com
}

\begin{abstract}
RESUMO
Os motores convertidos para gás natural geralmente emitem grandes quantidades de hidrocarbonetos não queimados devido à má qualidade dos dispositivos de conversão. A tecnologia dos motores a gás natural tem sido aplicada comercialmente em motores de ciclo Otto, mas ainda é incipiente em motores de ciclo Diesel. É necessário melhorar a tecnologia dos motores bicombustível de ignição por compressão, conhecendo melhor suas características e seu funcionamento. Um dos itens pouco estudados é o ciclo real de funcionamento de um motor bicombustível, trabalhando simultaneamente com Diesel e gás natural. O objetivo deste trabalho é estudar as diferenças existentes no diagrama de pressões dentro do cilindro de um motor Diesel, trabalhando em regime bicombustível (Diesel - gás natural). Os testes foram realizados em um motor Diesel adaptado para trabalhar em regime bicombustível com injeção eletrônica de gás. Foram feitos 10 ensaios dinamométricos com duração aproximada de 25 segundos para o motor trabalhando em regime Diesel e de bicombustível. O pico de pressão do motor trabalhando em regime Diesel apresentou valores mais baixos do que no regime bicombustível. No regime bicombustível o pico foi acentuado e de curta duração, aproximando do padrão de um ciclo Otto.
\end{abstract}

Palavras-chave: Motor Diesel, motor bicombustível, gás natural, óleo Diesel, diagrama de pressões, ensaio experimental.

\section{ABSTRACT}

The engines converted to natural gas usually emit great amounts of no burned fuel due to bad quality of the conversion devices. The technology of the natural gas engine has been applied commercially in the Otto cycle engines, but it is still incipient in engines of Diesel cycle. It is necessary to improve the technology of the dual-fuel engines, knowing their characteristics and its better operation. One of the items that there aren't sufficient studies is the real cycle of operation of a dual-fuel engine, working simultaneously with Diesel and natural gas. This work aims to study the existent differences in the diagram of pressures inside of a Diesel engine cylinder, running on Diesel regime and the same engine running under a dual fuel regime (diesel - natural gas). The tests were accomplished in Diesel engine purposely modified to run on dual-fuel regime with electronic injection of gas. Ten (10) experiments (test bench)were carried out with duration of 25 seconds for the engine running on Diesel and dual-fuel combustibles. The peak of pressure of the engine running in regime Diesel presented lower values than those observed for the dual-fuel regime. In the dual-fuel regime, the peak was accentuated and it has a short duration, approximating of the pattern of an Ottocycle.

Keywords: Diesel engine, dual-fuel engine, natural gas, Diesel oil, diagram of pressures, experimental investigation.

\section{1 - INTRODUÇÃO}

Após um crescimento acentuado da demanda por veículos convertidos para gás natural nos últimos anos no Brasil, tornou-se necessário melhorar a qualidade das conversões, criando tecnologias mais eficientes. $\mathrm{Na}$ atualidade são utilizados dois tipos de motores veiculares: os motores de ciclo Diesel (motores de ignição por compressão) (OZSOYSAL, 2006) empregados em veículos de carga, tratores e em algumas caminhonetes de turismo e os motores de ciclo Otto (HOU, 2007; CULLEN; MCGOVERN, 2010) (motores de ignição por centelha) usados nos automóveis e na maioria das caminhonetes leves.
A possibilidade de usar gás natural em motores Diesel também abre um leque de oportunidades no meio agrícola onde a principal fonte de energia é o motor Diesel. E o este tipo de combustível representa uma parcela considerável no custo da produção. Segundo experimentos realizados por Camargo (2003), o melhor rendimento do motor bicombustível (OZSOYSAL, 2009; MATTARELLI; RINALDINI; GOLOVITCHEV, 2014) testado se dá para um consumo médio de 100 litros de gás natural por $\mathrm{kWh}$ e 49 gramas de óleo Diesel por kWh, o que significa $22 \%$ de consumo de óleo Diesel em relação ao mesmo motor trabalhando somente com Diesel. Nestas condições há uma redução no custo do combustível em torno de $46 \%$. 
Nos motores bicombustíveis (MCTAGGARTCOWAN, 2010) o gás natural é introduzido sob baixa pressão no coletor de admissão, onde é misturado com o ar que está sendo aspirado pelo motor. Esta mistura de ar e combustível é comprimida pelo motor sem entrar em ignição espontânea. Considerando que o gás natural tem um índice de octanas superior a 145 (MON - motor octane number). Assim, suporta a taxa de compressão de um motor Diesel. Ao final do ciclo de compressão, a bomba injetora injeta uma pequena quantidade de óleo Diesel.

O óleo Diesel injetado, ao encontrar um ambiente favorável em oxigênio, temperatura e pressão, entra em ignição, produzindo uma chama que dá início à combustão (ENWEREMADU; RUTTO, 2010) do combustível principal (gás natural). O óleo Diesel injetado produz apenas uma chama piloto no momento correto definido pela bomba injetora. $\mathrm{O}$ uso de motores a Diesel bicombustível reduz o consumo de óleo Diesel que passa a ser parcialmente substituído pelo gás natural. Em uma primeira etapa é necessário melhorar a tecnologia dos motores bicombustível de ignição por compressão. Conhecendo melhor suas características e seu funcionamento, para então em uma segunda etapa, com a tecnologia já consolidada, partir para soluções alternativas e entre estas o uso de biogás no lugar de gás natural.

Muitos fatores importantes na caracterização do motor bicombustível ainda não foram estudados. Entre estes, um item relevante no estudo de um motor é o seu ciclo real. Os motores de ciclo Diesel e os motores de ciclo Otto já tiveram seus ciclos de funcionamento (diagrama pressãovolume) exaustivamente estudados. Entretanto, existem poucas informações sobre o ciclo real de um motor bicombustível (Diesel e gás natural). Desta forma, fica caracterizado como um problema o desconhecimento do diagrama pressão-volume do motor bicombustível (XIA; CHEN; SUN, 2012), trabalhando simultaneamente com Diesel e gás natural.

O gás natural (KATES, 1970; ABREU, 1999) é uma substância composta por uma mistura de hidrocarbonetos leves, basicamente metano, uma pequena parcela de etano e outros componentes, que pode ou não estar associado ao petróleo. À temperatura ambiente e pressão atmosférica permanece em estado gasoso. Apresenta baixos teores de contaminantes e é quase isento de enxofre. O gás natural, devido ao baixo índice de cetano, não é adequado para ser usado como combustível de motores de ignição por compressão. A mistura ar-gás oferece dificuldade para iniciar a combustão (LEE; LEE; PARK, 2010) apenas pela compressão, entretanto, tem uma grande facilidade para entrar em combustão por centelha ou uma chama já iniciada por outro meio. Esta característica permite que este combustível seja empregado com facilidade nos motores de ciclo Otto. Uma solução prática é o funcionamento de motores de ciclo Diesel (TAT, 2011) com dois combustíveis: óleo Diesel e gás, ou seja, motores bicombustíveis.

O rendimento termodinâmico (GIACOSA, 1986; GORJI; REGGIAN; SANDROLINI, 2013) de um motor aumenta com o aumento da taxa de compressão. Nos motores de ignição por compressão, como a taxa de compressão é mais alta, o rendimento termodinâmico também é maior. O índice de cetano (GIACOSA, 1986; LAPUERTA; RODRÍGUEZ-FERNÁNDEZ; ARMAS, 2010) é empírico e mede a maior ou menor facilidade que o combustível tem para entrar em ignição espontânea quando submetido a altas pressões em presença de oxigênio. O índice de octanas (BRADLEY; HEAD, 2006) é, também, um índice empírico que mede a maior ou menor facilidade que o combustível tem para suportar pressões elevadas quando em presença de ar, sem entrar em ignição espontânea.

Neste trabalho foi determinado o ciclo real de um motor de combustão por compressão, trabalhando em regime bicombustível em diferentes regimes de carga e rotação. Foram, ainda, comparadas as diferenças existentes com o ciclo Diesel do mesmo motor em idênticas condições de trabalho. Desta forma foi levantada a seguinte Hipótese: A introdução de um combustível gasoso em motor Diesel funcionando em regime bicombustível aumenta a pressão interna dentro do cilindro, proporcionando maiores torques em rotações de trabalho normais nos regimes de utilização.

\section{2 - MATERIAIS E MÉTODOS}

Primeiramente foi realizada uma revisão bibliográfica referente ao biodiesel e em relação à sua importância, como energia renovável. Quanto ao desenvolvimento do experimento foi utilizado um motor Diesel mono cilíndrico marca Agrale, modelo M90, com torque máximo nominal de $35,58 \mathrm{Nm}$ a 1800 rotações por minuto (rpm) e potência máxima nominal de $8,8 \mathrm{~kW}$ a $2750 \mathrm{rpm}$. O motor foi instalado em um dinamômetro de absorção hidráulica onde foram feitos os ensaios dinamométricos, trabalhando em regime Diesel e bicombustível. Na Figura 1 é mostrado o motor já instalado no dinamômetro, em condições de iniciar os ensaios.

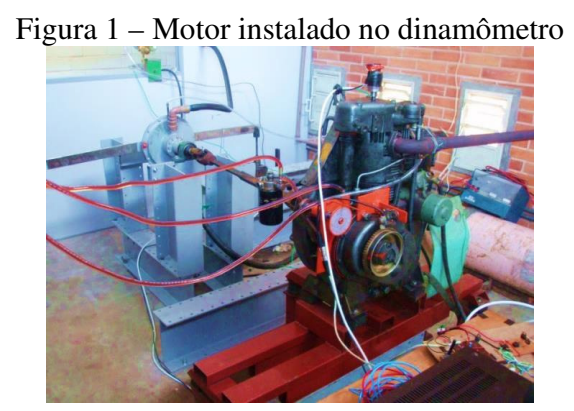

Para possibilitar o funcionamento no regime bicombustível foi desenvolvido um sistema baseado em circuito eletrônico micro processado, o qual teve como objetivo gerenciar a injeção do gás natural no coletor de admissão do motor. $\mathrm{O}$ sistema eletrônico consistiu de uma CPU projetada com base em um microcontrolador PIC18F452 e de uma unidade de potência onde foi utilizada uma chave de potência tipo MOSFET IRFZ46N. Como interface de comunicação foi utilizada uma placa de aquisição de dados Measurement Computing modelo USB 1208FS. Como atuador foi utilizado um bico injetor de gasolina, modificado de modo que o mesmo pudesse 
trabalhar com gás natural. As alterações feitas no bico injetor consistiram da remoção do atomizador, existente na sua extremidade; a remoção do filtro de combustível na entrada e no alargamento do canal de saída de combustível.

$\mathrm{O}$ alargamento do canal foi necessário para se obter uma vazão maior. Como a densidade do gás é menor que a densidade da gasolina, para quantidades equivalentes de combustível a vazão de gás é muito maior. A remoção do filtro foi necessária também para aumentar a vazão, já que o gás não necessita ser filtrado. $\mathrm{O}$ atomizador também foi retirado porque o gás não necessita ser atomizado para facilitar a mistura com o ar. A injeção mecânica de óleo Diesel foi mantida. Devido ao escopo do experimento, que era testar um motor bicombustível, o controle de rotação máxima não poderia ser utilizado, uma vez regulado o débito da bomba injetora para apenas um percentual do débito máximo, estaria se determinando uma rotação máxima. Ao complementar com gás natural a rotação tenderia a aumentar, e então, seria acionado o dispositivo limitador de rotação cortando o combustível Diesel necessário para promover a ignição do gás. Para possibilitar a execução dos ensaios optou-se por retirar os contrapesos do sistema de controle de rotação máxima.

A aceleração da bomba injetora foi mantida em uma posição que correspondia a $22 \%$ do débito máximo de combustível do motor trabalhando em regime Diesel e a aceleração do motor foi controlada pela injeção eletrônica de gás natural. Durante os ensaios dinamométricos a vazão de gás natural foi mantida em 100 litros de gás por kWh. Na Figura 2 é mostrado um exemplo de resultados parciais meramente ilustrativos, com o fim de mostrar como foram obtidos os dados, estão apresentadas as curvas obtidas de um ciclo completo de funcionamento do motor ensaiado. Estas curvas representam uma rotação do motor trabalhando com óleo Diesel a $2.000 \mathrm{rpm}$, sob carga ao freio e aceleração plena.



Para que fosse possível fornecer a quantidade adequada de combustível e na posição angular correta do motor, o microprocessador necessitava registrar a rotação do motor e a posição do cilindro. Foi instalado um sistema de medição da rotação do motor. Para o gerenciamento eletrônico empregou-se um microcontrolador modelo PIC18F452, fabricado pela MicrochipTechnologyInc. No circuito de potência para o injetor foi utilizada uma chave de potência do tipo MOSFET IRFZ46N e de um circuito integrado UC3708. Como interface de comunicação para a transmissão de dados da CPU para o computador foi utilizada uma placa de aquisição de dados Measurement Computing modelo USB-1208FS. Esta placa foi programada para uma taxa de aquisição de dados de 10.000 aquisições por segundo. Com esta taxa de aquisição foi possível determinar a forma da curva de pressões dentro do cilindro, mesmo com o motor trabalhando em alta rotação.

Para determinar as pressões dentro do cilindro do motor e consequentemente o ciclo real (diagrama pressão volume) foi utilizado um sensor eletrônico de pressão, marca NationalSemicoductor, modelo LX1603G. O sensor foi montado em uma pequena placa de circuito impresso, especialmente desenvolvida para ele (Figura 3).
Figura 3 - Sensor de pressão montado na placa de circuito impresso

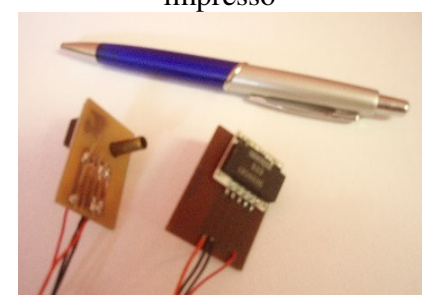

Por ser um sensor eletrônico, o mesmo tem sensibilidade a temperaturas elevadas, portanto não poderia ser instalado diretamente dentro da câmara de combustão. Por outro lado, um simples tubo de comunicação entre a câmara de combustão e o sensor externamente colocado a uma distância suficientemente grande para não sobre aquecer, causaria uma modificação na taxa de compressão, devido ao aumento do volume da câmara de combustão. Isto alteraria as características do motor ou até impediria o seu correto funcionamento.

Outra agravante era a grande pressão existente na câmara de combustão durante a queima dos gases, considerando que a faixa de pressão suportada pelo sensor era inferior. Para resolver esse problema foi projetado e construído um dispositivo mecânico que transferia e condicionava a pressão interna do cilindro para ser registrada pelo sensor. Para resolver o problema foi projetado e construído o dispositivo mostrado na Figura 4. 
Figura 4 - Dispositivo condicionador de pressão do sensor da câmara de combustão

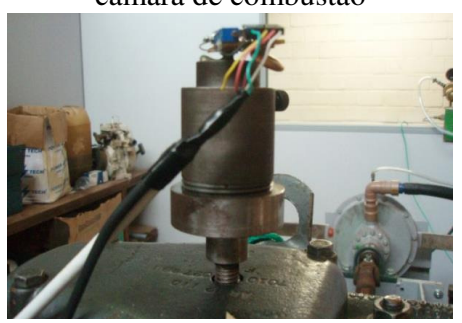

O dispositivo consiste de um tubo de aço com furo calibrado, por onde pode se deslocar uma haste de $4 \mathrm{~mm}$ sem deixar vazar pressão. Este tubo possui uma rosca em uma extremidade pela qual se fixa à tampa de cilindro (cabeçote) do motor, através de um furo convenientemente disposto e na outra extremidade outra rosca faz a fixação com a base de um cilindro hidráulico, na Figura 5 é mostrada a furação do cabeçote para a instalação do tubo.

Figura 5 - Furação da câmara de combustão

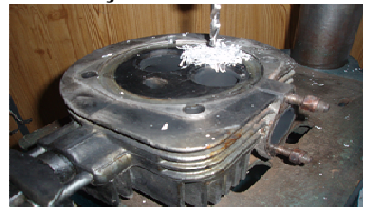

Na Figura 6 é mostrado o referido tubo já instalado no cabeçote e com a base do cilindro hidráulico já montado na sua outra extremidade.

Figura 6 - Fixação do tubo de furo calibrado no cabeçote, com a base do cilindro hidráulico



Dentro do furo calibrado do tubo foi instalado uma haste com diâmetro de $4 \mathrm{~mm}$ também calibrada. Esta haste transmite a pressão da câmara de combustão para um embolo instalado dentro do cilindro hidráulico, no qual foi montado o sensor de pressão. Na Figura 7 é mostrado o cilindro hidráulico montado, já com o sensor de pressão, pronto para ser "rosqueado" na extremidade do tubo calibrado já instalado no cabeçote do motor.

Figura 8 - Ciclo completo do motor para a rotação de $2.000 \mathrm{rpm}$

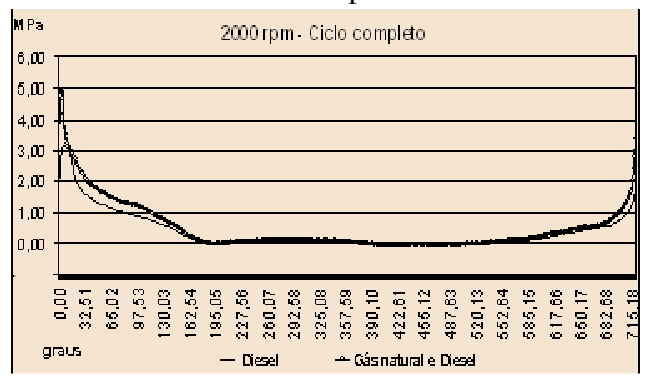

Figura 7 - Cilindro hidráulico com haste e o sensor de pressão já instalados



Após a preparação do motor foram feitos ensaios sob carga. Em cada ensaio o motor era posto a funcionar em regime Diesel com aceleração pré-estabelecida de $22 \%$ da plena aceleração e progressivamente, à medida que era aplicada a carga, ia sendo injetado gás natural no motor até atingir o valor pré-estabelecido 100 litros de gás por kWh, com rotação de $1.800 \mathrm{rpm}$ (rotação de marcha lenta estabelecida pelo fabricante). Quando estas condições eram atingidas iniciava-se a aquisição de dados e a carga ia sendo progressivamente reduzida, sem alterar as condições de aceleração, até o motor atingir a rotação máxima estabelecida pelo fabricante $(2800 \mathrm{rpm})$. O mesmo foi feito sem gás natural e acelerando o motor somente com óleo Diesel como combustível.

A análise das curvas de pressão dentro do cilindro se deu por meio de 10 ciclos completos do motor para rotações definidas de 200 em 200 rpm entre 1.800 e 2.800 rpm, com o motor funcionando em regime bicombustível e outras 10 em regime Diesel. Os dados de pressão foram agrupados em função do ângulo de giro do virabrequim, e para cada ângulo encontrado foi feita uma média dos dados dos 10 ensaios selecionados. Assim conseguiu-se obter dados mais representativos das pressões dentro do cilindro.

\section{3 - RESULTADOS E DISCUSSÕES}

Inicialmente foi feita a análise das curvas (Figuras 8, 9, 10, $11,12,13$ e 14) de pressão dentro do cilindro do motor para se obter o diagrama de pressões e, consequentemente, o ciclo real. Foram tomados os valores das pressões médias, ponto a ponto, e com estes dados previamente selecionados foram montadas planilhas separadas para cada faixa de rotação pré-estabelecida e divididas por ciclos de funcionamento do motor: ciclo de expansão; ciclo de exaustão; ciclo de aspiração e ciclo de compressão.

Figura 9 - Pressão no interior do cilindro com rotação de $1.800 \mathrm{rpm}$




Figura 10 - Pressão no interior do cilindro no ciclo de expansão com rotação de $2.000 \mathrm{rpm}$

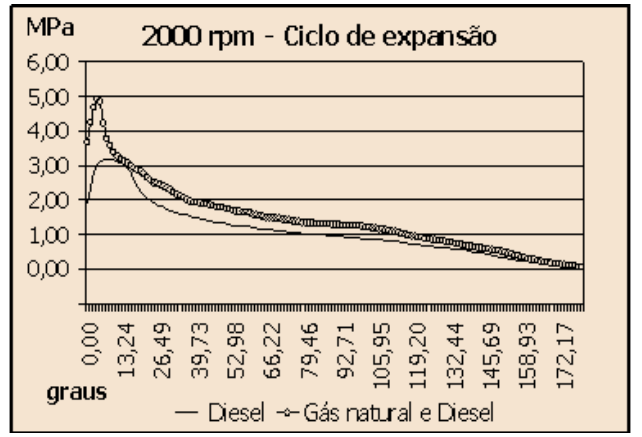

Figura 12 - Pressão no interior do cilindro no ciclo de expansão com rotação de $2.400 \mathrm{rpm}$



Figura 14 - Pressão no interior do cilindro no ciclo de expansão com rotação de $2.800 \mathrm{rpm}$



A interpretação das curvas do ciclo de expansão implica que:

- O pico de pressão é maior no regime bicombustível porque após o início da combustão a queima do combustível ocorre como se fosse um ciclo Otto e este, com a taxa de compressão de um motor Diesel, desenvolve uma pressão maior, por outro lado como a combustão no ciclo Otto ocorre com volume constante, em um tempo pequeno, o pico de pressão é naturalmente maior do que no ciclo Diesel.

- O pico de pressão no regime Diesel, além de ser menor, apresenta um pequeno achatamento em seu topo, o que é explicado pela combustão do Diesel que ocorre à pressão constante.

- Com o aumento da rotação do motor há uma diminuição das pressões, tanto no regime Diesel como no regime bicombustível. Esse fato pode ser explicado pelo menor enchimento do cilindro no ciclo de admissão devido às perdas de carga no sistema de

Figura 15 - Curvas de pressão dentro do cilindro no ciclo de
Figura 11 - Pressão no interior do cilindro no ciclo de expansão com rotação de $2.200 \mathrm{rpm}$

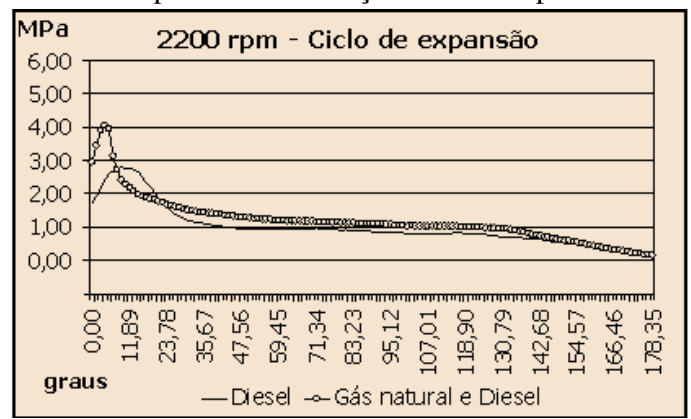

Figura 13 - Pressão no interior do cilindro no ciclo de expansão com rotação de $2.600 \mathrm{rpm}$

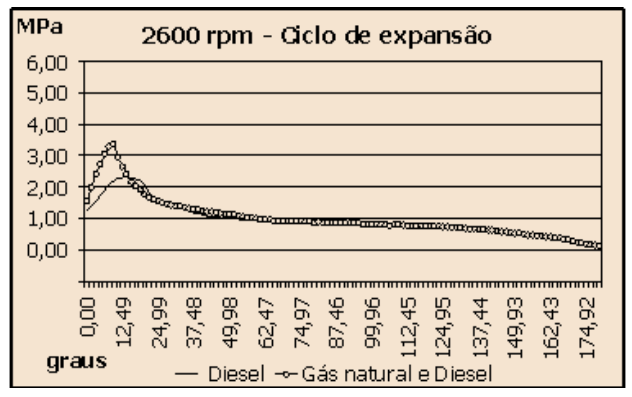

alimentação, que aumentam com a velocidade do motor, já que este motor é um motor de aspiração natural não sobrealimentado.

- Com o aumento da rotação observou-se um deslocamento dos picos de pressão, retardando esta ocorrência. Com o aumento da rotação, o tempo disponível para a queima é menor. Como este motor não dispõe de nenhum sistema de avanço automático do ponto de início da injeção de combustível, para compensar o aumento da velocidade, é natural que ocorra um retardo na ocorrência dos picos de pressão.

Analisando as curvas do ciclo de exaustão para todas as faixas de rotação selecionadas observou-se que não existem diferenças significativas entre os ensaios com o motor trabalhando em regime Diesel e em regime bicombustível. O mesmo é válido para as curvas dos ciclos de admissão. O comportamento das curvas do ciclo de compressão pode ser observado nas Figuras 15, 16, 17, 18, 19 e 20.

Figura 16 - Curvas de pressão dentro do cilindro no ciclo 


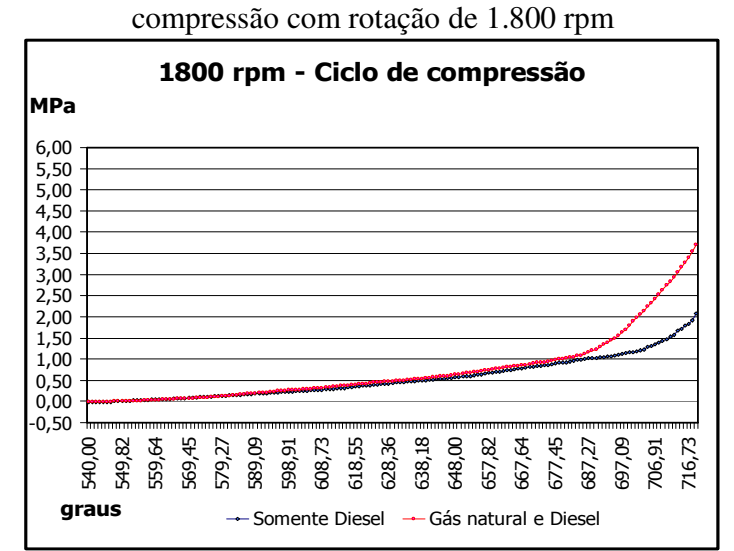

Figura 17 - Curvas de pressão dentro do cilindro no ciclo de compressão com rotação de $2.200 \mathrm{rpm}$

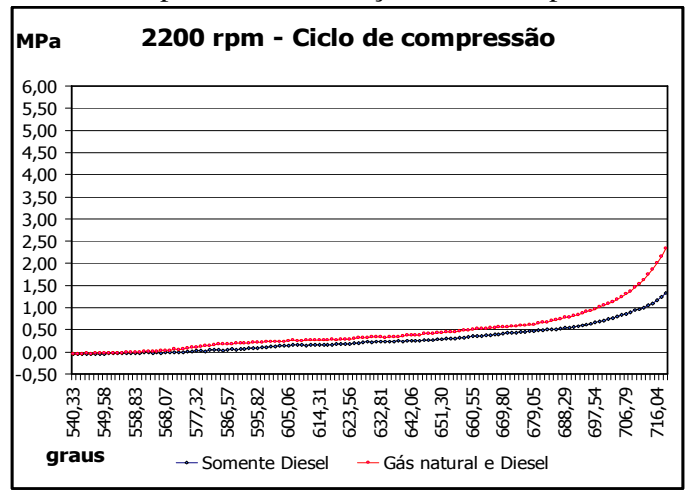

Figura 19 - Curvas de pressão dentro do cilindro no ciclo de compressão com rotação de $2.600 \mathrm{rpm}$

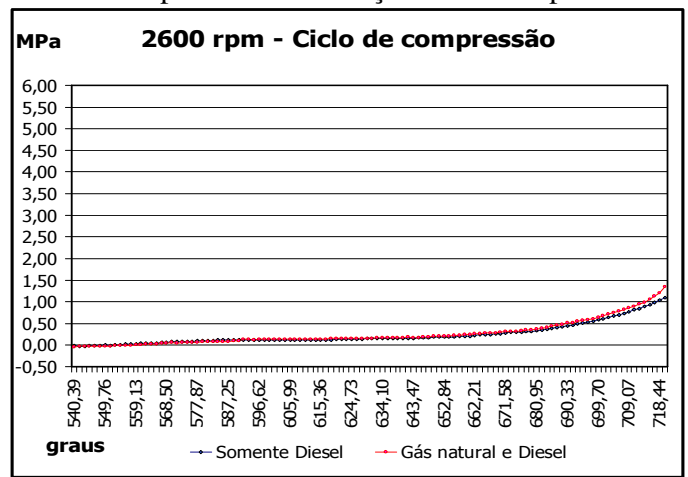

Assim a interpretação das curvas do ciclo de compressão mostra que:

- Um aumento crescente e uniforme da pressão até início da injeção de combustível e início da ignição.

- A partir do ponto de início da injeção de combustível Diesel, inicia-se a queima do combustível com um aumento significativo da pressão.

- Como este motor não dispõe de avanço automático do ponto de injeção de combustível, variável com a rotação do motor, pode-se observar as seguintes anomalias:

- Nas baixas rotações como o tempo disponível para se realizar a queima do combustível é maior e o ponto de início da injeção é sempre o mesmo, a pressão aumenta, ainda no ciclo de compressão, de compressão com rotação de 2.000 rpm

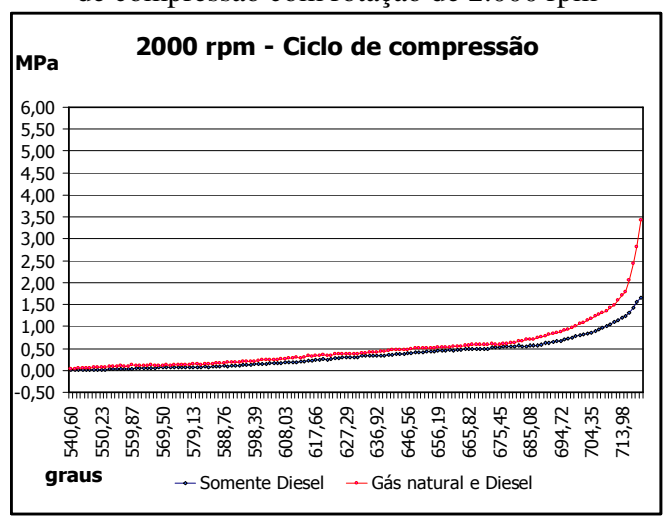

Figura 18 - Curvas de pressão dentro do cilindro no ciclo de compressão com rotação de $2.400 \mathrm{rpm}$

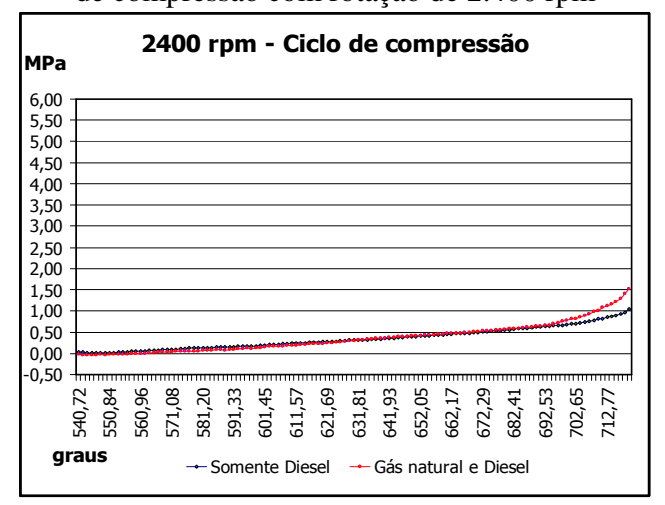

Figura 20 - Curvas de pressão dentro do cilindro no ciclo de compressão com rotação de $2.800 \mathrm{rpm}$



gerando forças que se opõe ao movimento do motor, diminuindo o rendimento do mesmo.

- Com o aumento da rotação observou-se um retardamento no aumento da pressão. Isto causa um deslocamento dos picos de pressão do ciclo de expansão, causando também diminuição do rendimento do motor. Com o aumento da rotação, o tempo disponível para a queima é menor. Como este motor não dispõe de nenhum sistema de avanço automático do ponto de início da injeção de combustível, para compensar o aumento da velocidade, é natural que ocorra estes desvios que diminuem o rendimento do motor.

Para calcular a pressão média foi considerado que todas as fases do ciclo de um motor consomem energia, com exceção do ciclo de expansão, que transforma o calor 
gerado pela queima do combustível em energia mecânica útil. A energia mecânica gerada no ciclo de expansão deve compensar a energia absorvida nos demais ciclos e ainda sobrar energia mecânica líquida no eixo do motor. Então, foi feito um cálculo ponto a ponto, subtraindo da pressão do ciclo de expansão as pressões dos demais ciclos em valores absolutos. Os valores obtidos são os valores líquidos de pressão disponíveis para determinar o torque disponível no motor.

Figura 21 - Curva de oxigênio livre (ensaio feito sem carga)

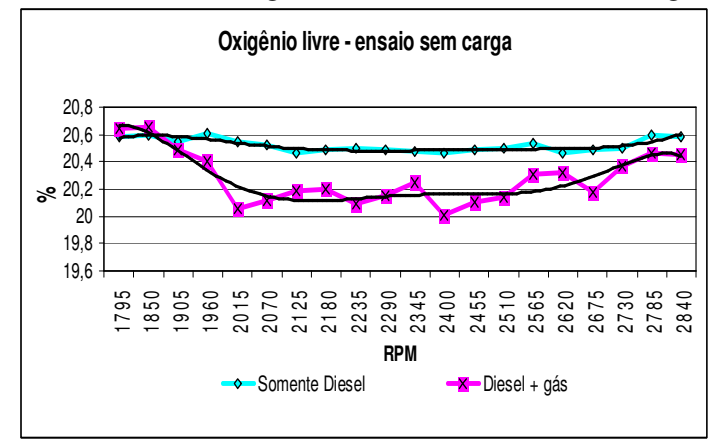

Nas Figuras 23 e 24 são apresentados os valores de dióxido de carbono e monóxido de carbono, respectivamente, encontrados nas emissões.

Figura 23 - Emissões de dióxido de carbono.



As curvas de dióxido de carbono foram obtidas sob carga em um ensaio dinamométrico. Pode-se observar que

Figura 25 - Emissões de $\mathrm{SO}_{2}$

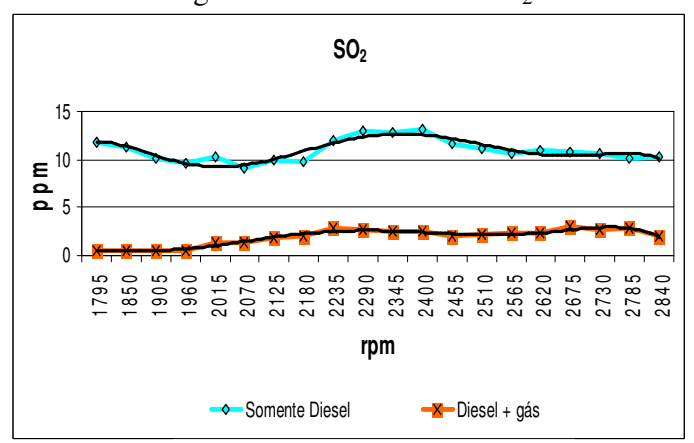

\subsection{Análise de emissões}

Observa-se, nas Figuras 21 e 22, que quando o motor foi submetido a um esforço (durante um ensaio dinamométrico com máximo carregamento) houve uma maior uniformidade nos valores do oxigênio livre. O ensaio usando óleo Diesel e gás natural apresentou menores valores de oxigênio livre. Nas rotações médias, para o ensaio com gás natural, os valores obtidos foram menores.

Figura 22 - Curva de oxigênio livre (ensaio feito com carga)

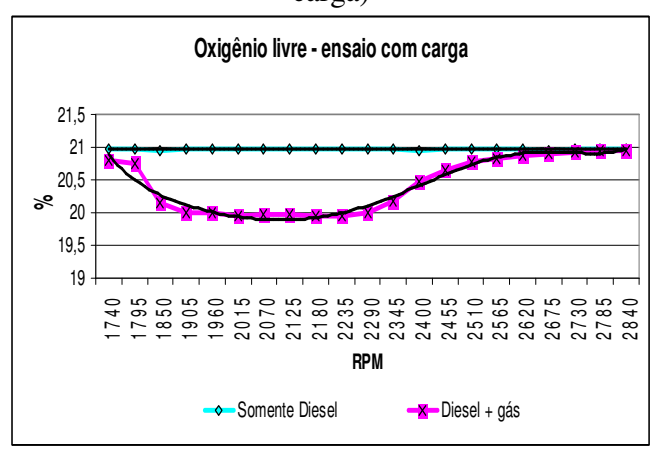

Figura 24 - Emissões de monóxido de carbono

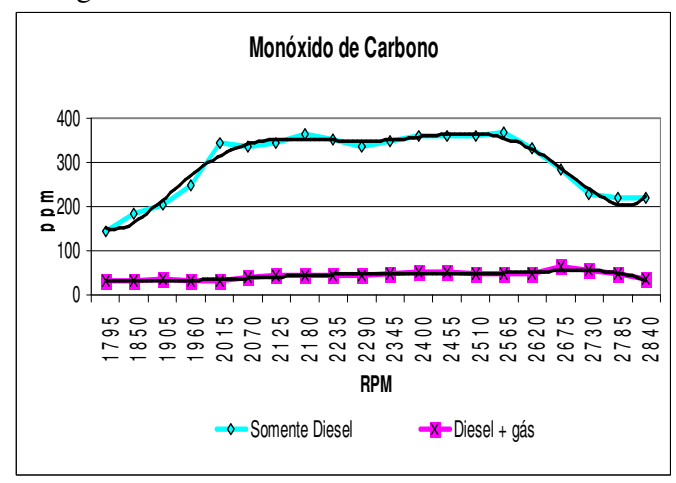

em médias rotações há um acréscimo significativo de $\mathrm{CO}_{2}$ quando o motor trabalha somente com óleo Diesel.

Nas curvas das Figura 25 e 26 são representadas as emissões de $\mathrm{SO}_{2}$ e hidrocarbonetos, respectivamente.

Figura 26 - Hidrocarbonetos não queimados

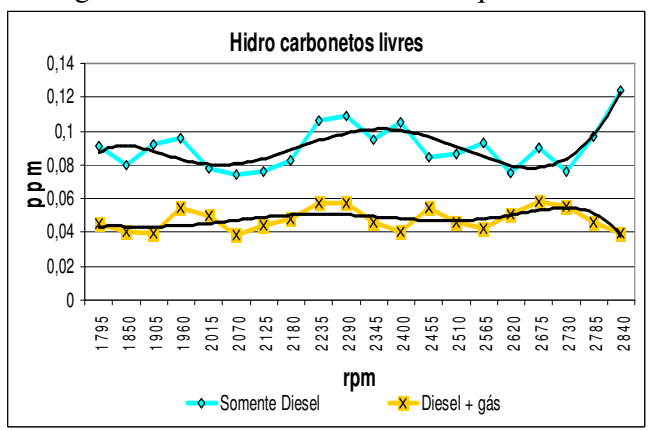


As curvas de hidrocarbonetos livres foram obtidas sob carga em um ensaio dinamométrico. Devido à natureza gasosa do gás natural, a qualidade da combustão é melhor do que somente óleo Diesel, dessa forma sobra menos combustível não queimado nos gases emitidos. Observando-se o resultado das análises de gases, pode-se ver que o regime bicombustível apresentou menor quantidade de emissões poluentes que o regime Diesel.

Portanto, baseado nos resultados obtidos pode-se concluir que a hipótese formulada: "A introdução de um combustível gasoso em um motor Diesel funcionando em regime bicombustível aumenta a pressão interna dentro do cilindro, proporcionando maiores torques em rotações de trabalho normais nos regimes de utilização" é verdadeira.

\section{CONCLUSÕES}

Nas condições em que foram realizados os ensaios e baseado nos resultados obtidos, foram traçadas as curvas que representam os diagramas de pressão em relação aos graus de giro do virabrequim. O pico de pressão é maior no regime bicombustível, porque, após o início da combustão a queima do combustível ocorre como se fosse um ciclo Otto e este, com a taxa de compressão de um motor Diesel, desenvolve uma pressão maior. Por outro lado, como a combustão, no ciclo Otto ocorre com volume constante, em um tempo pequeno, o pico de pressão é naturalmente maior do que no ciclo Diesel.

O pico de pressão no regime Diesel, além de ser menor, apresenta um pequeno achatamento em seu topo, o que é explicado pela combustão do regime Diesel que ocorre à pressão constante. Com o aumento da rotação do motor há uma diminuição das pressões, tanto no regime Diesel como no regime bicombustível. Este fato pode ser explicado pelo menor enchimento do cilindro no ciclo de admissão devido às perdas de carga no sistema de alimentação, que aumentam com a velocidade do motor, já que este motor é um motor de aspiração natural não sobrealimentado.

Com o aumento da rotação observou-se um deslocamento dos picos de pressão, retardando esta ocorrência. Com o aumento da rotação, o tempo disponível para a queima é menor. Como este motor não dispõe de nenhum sistema de avanço automático do ponto de início da injeção de combustível, para compensar o aumento da velocidade, é natural que ocorra um retardo na ocorrência dos picos de pressão. Para qualquer regime de rotação os valores dos picos de pressão são sempre maiores no regime bicombustível do que no regime Diesel. Por fim, os aspectos analisados são positivos, o biodiesel é um combustível sustentável, e os benefícios sociais que podem ser alcançados são visíveis.

Assim, algumas recomendações futuras podem ser úteis para se dar seguimento a este trabalho.

- É recomendável fazer outros ensaios no dinamômetro com motores multicilíndricos, com variações menores de rotações, de percentagem de Diesel e de vazão de gás natural. E, também com determinação dos dados da sonda lambda e análise dos gases de escapamento, para formar um banco de dados que possa servir de base para um mapeamento global do motor.

- De posse do mapeamento, pode-se melhorar o sistema de gerenciamento computadorizado de injeção de gás, otimizando o desempenho para cada instante, como em um motor de ciclo Otto com injeção eletrônica de combustível.

- É recomendável projetar um bico injetor dedicado para gás natural com debito de gás adequado a motores veiculares e de maquinário agrícola.

- Podem ser projetados e fabricados conjuntos comerciais que possam ser adaptados a qualquer veículo Diesel, ou motor estacionário, utilizando a tecnologia desenvolvida.

Para que se possam implantar tecnologias novas, que provoquem uma mudança de conceitos é necessário que sejam desenvolvidas exaustivamente pesquisas de base, de modo a se ter um completo conhecimento científico do assunto.

Neste contexto é de fundamental importância o estudo do ciclo real de funcionamento de um motor bicombustível, trabalhando simultaneamente com Diesel e gás natural. Esse tipo de motor torna-se uma ferramenta importante para controle da poluição atmosférica, sendo que, o gás natural veicular poderá reduzir em grande proporção as emissões poluentes. No que diz respeito às questões relativas ao meio ambiente, a utilização de biodiesel como combustível torna-se uma grande prioridade para o mundo inteiro, pela sua enorme contribuição ao meio ambiente, com a redução qualitativa e quantitativa dos níveis de poluição ambiental.

Portanto, a troca do Diesel pelo biodiesel melhora a qualidade do ar e, por conseguinte a qualidade de vida da população

\section{REFERÊNCIAS}

ABREU, P. L.; MARTINEZ, J. A. Gás natural o combustível do novo milênio. Porto Alegre: Plural Comunicações, 1999.90 p.

BRADLEY, D.; HEAD, R. A. Engine autoignition: the relationship between octane numbers and autoignition delay times. Combustion and Flame, v. 147, n. 3, p. 171184, 2006.

CULLEN, B.; MCGOVERN, J. Energy system feasibility study of an Otto cycle-Stirling cycle hybrid automotive engine. Energy, v. 35, n. 2, p. 1017-1023, 2010.

ENWEREMADU, C. C; RUTTO, H. L. Combustion, emission and engine performance characteristics of used cooking oil biodiesel: a review. Renewable and Sustainable Energy Reviews, v. 14, n. 9, p. 2863-2873, 2010.

GIACOSA, D. Motores endotérmicos. Madrid: Editorial Dossat, 1986. 722 p.

GORJI, N. E.; REGGIANI, U.; SANDROLINI, L. Auger generation effect on the thermodynamic efficiency of $\mathrm{Cu}(\mathrm{In}, \mathrm{Ga}) \mathrm{Se}_{2}$ thin film solar cells. Thin Solid Films, v. 537, p. 2285-2290, 2013.

HOU, Shuhn-Shyurng. Comparison of performances of air standard Atkinson and Otto cycles with heat transfer 
considerations. Energy Conversion and Management, v. 48, n. 5, p. 1683-1690, 2007.

KATES, J. E. Diesel and high compression gas engines. Chicago: American Technical Society, 1970. 445 p.

LAPUERTA, M., RODRÍGUEZ-FERNÁNDEZ, J., ARMAS, O. Correlation for the estimation of the density of fatty acid esters fuels and its implications: a proposed Biodiesel Cetane Index. Chemistry and Physics of Lipids, v. 163, n. 7, p. 720-727, 2010.

LEE, D. H.; LEE, J. S.; PARK, J. S. Effects of secondary combustion on efficiencies and emission reduction in the Diesel engine exhaust heat recovery system. Applied Energy, v. 87, n. 5, p. 1716-1721, 2010.

MATTARELLI, E.; RINALDINI, C. A.; GOLOVITCHEV, V. I. CFD-3D analysis of a light duty dual fuel (Diesel - natural gas) combustion engine. Energy Procedia, v. 45, p. 7929-7937, 2014.

MCTAGGART-COWAN, G. P. The influence of fuel composition on a heavy-duty, natural-gas direct-injection engine. Fuel, v. 89, n. 3, p. 752-759, 2010.

OZSOYSAL, O. A. Effects of combustion efficiency on a Dual cycle. Energy Conversion and Management, v. 50, n. 9, p. 2400-2406, 2009.

OZSOYSAL, O. A. Heat loss as a percentage of fuel's energy in air standard Otto and Diesel cycles. Energy Conversion and Management, v. 47, n. 7-8, p. 10511062, 2006.

TAT, M. E. Cetane number effect on the energetic and exergetic efficiency of a Diesel engine fuelled with biodiesel. Fuel Processing Technology, v. 92, n. 7, p. 1311-1321, 2011.

XIA, S.; CHEN, L.; SUN, F. Engine performance improved by controlling piston motion: linear phenomenological law system Diesel cycle. International Journal of Thermal Sciences, v. 51, p. 163-174, 2012. 